\title{
A Morte e o Ensino Médico
}

\section{Death and Medical Education}

Carlos Alberto Pessoa Rosa ${ }^{1}$

"A ausência é também uma morte, a única eimportante diferença éa esperança."

JoséSaramago

\section{DESCRTIORES:}

\section{- Mortc}

- Atitude frente at morts:

- Eslucaçāo médica

\section{KEYWTORIDS}

-Death

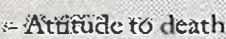

- Medical cducation

\section{ABSTRACT}

With the changes that have occurred in Medicinc, particularly in recent decades, death has been transferred from the family to the hospital environment. Doctors now find they need to deal with death and the dying. Only recently have medical schools become concerned with the subject. In Brazil, isolated endeavors have resulted from the personal concerns of psychologists, nurses and doctors. The responses obtained in the present report underline the need to include this subject in the Medicine curriculum. The subject of terminal illness is not a concern during undergraduate years and students thus often resort to denial and omnipotence to avoid suffering as far as possible. There should be a concern to educate, and not just instruct, both teachers who confess to being unprepared to discuss the subject, and students.

\section{INTRODUÇĀO}

Com um primo que apresentava uma cardiopa tia congênita cianótica, um avô que sofria de insuficiência cardíaca, uma cirurgia desnecessária de amígdalas e urna mãe igual a tantas outras, que saíacorrendo com o filho ao primeiro sinal de sangue, não seria preciso muitoesforço

I Formado na FCMSCSP' em 1976, Professor Assistente de Clínica Médica da LISF - Campus de Bragrança Paulista, escrilor e membro das Suciedudes Brasileiras de Clinicn Médica, Ciardiologia, Médicos Escritores e Binética. 
para merecordar de situaçōes que envolveram a atuação de um médico. O olhar de criança, sempre de baixo para cima, idolatrava o homem de branco, mistura de ideais positivistas ealgo de xamā, manipulador de aparelhos estranhos eolhar de feiticeiro. Tudo ao redor deles falava devida, nunca de morte. Nāo me lembro de uma crítica dirigida a um médico, mesmo quando as pessoas morriam. Uma consulta médica envolvia um ritual de águas e cheiros, de cotonetes enfiados em nossos orifícios e de dentifrícios, derecomendaçōes de silêncioe respeito. A recepçāo era uma nave de igreja gótica, e a roupa da enfermeira, quase sempre uma senhora dócil, serena eacolhedora, mas enérgica quando a situaçāo assim o exigia, impecavelmente engomada.

Portanto, nāo é difícil compreender que, nesse ambiente fantástico, qualquer vocaçāo para a profissāo não estava devidamente analisada. Ser médico envolvia a magia de dar a vida, nunca a morte. Dela trata o mito de Asclépio, que, ao tentar ressuscitar um morto, foi lançado ao Hades como castigo. Os humanos nāo têm esse poder, somente os deuses. O ser humano deve aprender a lidar com seus limites e impotências. Mas quem nos previne para o fato? De um mundo branconácar, observado obliquamente, caímosno infeno do formol e de corposinanimados. Cortamos courosem alma esangue, os membros rígidos e o olhar distante e sem brilho. Devemos ser fortes, assim devia ser, um ensinamento silente, inconsistente e sem convicçāo. Apresentados à morte sem ritual de passagem, sem preparo, sem nada. Parecia-me que todosnegavam o que os olhos demonstravam.

E os anos se passaram sem que ninguém, nenhum campo de estudos, nem mesmo a Psiquiatria, abordasse o assunto. Esta total negaçāo, fa to corriqueiro no dia-a-dia das pessoas, foi uma das responsáveis pela minha ida aodivā dopsicanalista, depois de formado. $\mathrm{O}$ assunto continua um tabu no meio universitário, onde jovens de sorrisos abertos têm, em pouco tempo, suas expressōes transformadas em pedra bruta. Vejo profissionais distantes do paciente e familiares, frios e calculistas, o olhar dirigido aos ponteiros das máquinas que soltam apitos e vapores. A distância aumenta mais e mais à medidaque a populaçāo começa a cobrardo médico tudo aquilo que a mídia, principalmentenorte-americana, promete, ou seja, a imortalidade. Que nāo somos deuses descobrimos todos os dias, mas o sofrimentopoderia ser muito menor, casc houvesse um preparo duranteo curso médico. Todos sabemos oresultado de um profissional paralisadopela ansiedade cpelo medo. De um lado, deparamoscomoperigo de alguns que, desafiando a morte em todos os poros, sāo cheios de bravura, indisciplinados e individualistas; de outro, sabemos que fracassos isolados levam ao suicídio, ao alcoolismo, a atos anti-sociais, abandono do emprego e à loucura psicótica e depressiva. É lógico que omedo responde por um aspecto concreto da realidade e exige sistemas defensivos específicos para superar seu sofrimento. O medo encontra-se em todas as atividades profissionais, mas é na Medicina que ele se dirige à consciência da própria morte, exigindo, do profissional de saúde, umpreparo mais particularizado.

Foi pensando na morte e nas possiveis conseqüências de sua negaçāo que me senti atraído pelo assunto. O médico nāo deve c nāo pode negá-la, anteo risco de ter sua saúde fisica ou mental afetada, se precisa conviver com ela diariamente, enós, professores de Medicina, temos a responsabilidade de apontar o problema e verificar a melhor forma de discuti-lo na universidade ${ }^{1-4}$.

\section{HISTÓRICO}

Orápido desenvol vimentotecnológico, associadoa novos enfoques terapêuticos ea uma mudança radical nas relaçōes humanas, conseqüuencia da forma do viver na modernidade, trouxe o paciente do ambiente familiarpara o hospital. Treinado para diagnosticar e restabelecer a saúde, o médico nāo o épara enfrentar a morte e o morrer (Durand et. al, 1990; Dyer, 1992; Dutscher, 1992) ${ }^{5}$. Como lidar com o fracasso, seos médicos nāo têm a oportunidade de discutir o próprio medo do fim? O dr. Feigenberg, oncologista epsiquiatra sueco, queixa-se que"embora a relação afetiva com o paciente terminal seja uma carga muito pesada, isso nāoé comumente reconhecido nem mesmo por outros psiquiatras, e ressente-se da dificuldade de partilhar suas emoçōes com outros profissionais devido ao silêncio dos mesmos" ${ }^{\prime \prime}$. Dentro de um universo de negaçāo, o ensino opta, segundo Maslow, "pela dessacralizaçāo como forma de defesa contra a invasão das emoçōcs, especialmentea do medo ${ }^{\text {"77.8. }}$. Osofrimentopode começar quando a evoluçāo doSujeito em relaçāo ao conteúdo doObjetoébloquea$\mathrm{da}{ }^{9,10}$. Poderāo surgir, entāo, as condutas defensivas, o afastamento dopaciente, ousodedrogas e osuicídio ${ }^{11}$. Pela complexidade do tema, nāo basta instruir o profissional,é necessárioeducá-lo para a morte e o morrer, oque, dada a complexidade do tema e das defesas impostas pelo sujeito, nāoć uma tarefa simples.

A negaçāo da morte acentua-se com o desenvolvimento industrial. De uma forma natural de se relacionar com o fim na Idade Média, caminhamos cada vez mais para a crença desermosimortais. Negaçāo eonipstência carninham de māos dadas. Nos Estados Unidos, a Royal Commission on Medical Education, em 1968, nāo faz referência ao ensino da morte e do morrcr. Somente em 1980, o Standing MedicalAdvisory Committee recomenda que seja incluído no curriculo médico um treinamento dos alunos com pacientes terminais, mas nāo deixa claro o conteúdo a ser seguido. O comitê de educaçāodo General Medical Council, en 1993, também enfatiza a 
importância de incluir o assunto no currículo médico ${ }^{12}$. Querem mais provas que estas para afirmar a negaçāo entre os profissionais desaúde?

Cappiello \& Troyer (1979) verificaram em Nova Iorque, que, entre 209 professores da área de saúde, $14,4 \%$ incl uiam algum preparo em seus currículos $\mathrm{c} 55 \%$ nāo o faziam de forma alguma. Lewis (1977), como diretor de um serviço de educaçāo $\mathrm{cm}$ um hospital na Califórnia, alerta para a breve abordagem sobre o tema epropōe experiências educacionais. Yarber et al. (1981), educadores em saúde da Universidade de $I$ afaiette, na Pensilvânia, enfatizam o papel da educaçāo dos prolissionais como recurso para treiná-los a melhor atender os pacientes terminais e propõem, com o objetivo de identificar as formas de ansiedade c o modo de controlá-las, cursos de educaçāo para a morte. Nos Estados Unidos, tem-se dado cada vez mais atençāo ao tema nos cursos de graduaçāo e pós-graduaçāo. Em 1992, 22 de 27 cursos médicos ofereciam cursos em medicina paliativa/terminal ${ }^{1:-16}$.

No Brasil, tivemos o seminário interdisciplinar sobre " $\wedge$ Morte e os Mortos", organizado por Souza-Martins (1982), que representou um momento importante de reflexāo ${ }^{17}$. Delá para cá, caminhamos muito pouco, e nāo temos nada oficial que regulamentc o ensino de tanatologia nas escolas médicas. Vivemos de pequenas ilhotas, flutuando ao acaso, muito mais por interesse individual que institucional. Nlgumas dessas ilhas devem ser citadas: "O tema morte: uma proposta de educaçāo", 1991, dogrupo orientadopor Elizabeth R. Martins do Valle, professora-doutora da Escola de Enfermagem de Ribeirāo Preto-USP; "A cducaçāo de alunos de graduaçāo em Enfermagem em relaçāo à morte e ao morrer", 1984, de M. A. Paduan; também de Ribeirāo Preto; "O ensino da problemática da morte nas escolas de saúde", realizado pelo Instituto de Pesquisas Psicossociais da Fundaçāo Getúlio Vargas, no Rio de Janeiro; "O psicólogo e a terminalidade", 1986, de Wilma da Costa Torres e Wanda Gurgel Gucdes, psicólogas do Isop; "Perfil da atitude médica diante do paciente terminal", 1994, c "Tanatologia - uma nova especialidade médico-psicológica", 1989, ambos de Evaldo A. D’ ^ssumpçāo, cirurgiāo plástico e tanatologista minciro ${ }^{18,19}$.

Em Bragança Paulista, abordamos o assunto na disciplina de Saúde \& Contexto. Procuramos introduzi-lo nas primeiras aulas do primeiro ano, quando o aluno entrava em contato com o curso de Anatomia. $\Lambda$ técnica utilizada foi a dramatizaçāodo mito de Asclépio, acrescentada de leitura de textos que tratassem do tema. Em 1997, ta mbém o curso de Psicologia Médica, oferecido pela Psiquia tria, passou a monitorar os alunos no internato. Infelizmente, apesar de sentirmos uma mudança na postura do acadêmico, a reforma curricular não rescrvou um espaço na grade curricular para que houvesse continuidade do trabalho. Foi realizadoainda, sob a coordenaçāodo Ifan - Insti tuto Franciscano de Antropologia -, um simpósio sobre "Temas de Bioética", coordenado pelo prof.dr. Alberto da Silva Moreira, quando foi apresentado "Omito de Asclépio e o médicolidando com a morte" pelo prof.dr. Roosevelt M.S. Cassorla, psicanalista c professor na Unicamp" 20 e "Mortalis: os médicos e a morte", pelo autor, publicados no cademon" 10 do Ifane, posteriormente em livro, pela editora Cone Sul.

\section{OBJETIVOS E MÉTODOS}

Oobjetivo deste trabalho foi traçar, com relaçāo ao tema, o perfil dos alunos, residentes e professores do curso de Medicina da USFquais experiências e (pre)conceitos trariam do meio social, que expectativas teriam em relaçāo à abordagem do tema duranteo curso, se elas foram completa ou parcialmente preenchidas, comosesentiriam depois de formados - e detectar se a escola cumpriu seu papel de educadora.

Num primeiro momento, o autor elaborou um questionário que foi discutido com o dr. Ernesto Jacob Keim, educador, cujas sugestōes foram sendo incorporadas até sc atingir um grau de clareza c facilidade de respostas que consideramos adequados. Dada a subjetividade do tema, trabalhamos com questōes fechadas e abertas, utilizando, sempre que necessário, textos literários que falassem direta ou indirctamente da morte. Acreditamos na importância das questōes abcrtas em funçāo de a fala, entendida enquanto discurso, passar pela revelaçāo do indivíduo enquanto Ser, contextualizado cultural e historicamente. $\Lambda$ s palavras foram dispostas em grupos afins, levando-se em conta seu caráter denotativo e conotativo. Questionário claborado, dividimos as perguntas em blocos, respeitando a diversidade da populaçāo estudada quanto à vivência acadêmica e experiência clínica.

Finalmente, em agosto de 1995, o questionário foi aplicado a estudantes do curso de Medicina, médicos residentes e professores das áreas clínicas (Cirurgia, Clínica Médica, Ginecologia e Obstetrícia, Ortopedia e Pediatria) do Hospital Universitário e da Iaculdade de Ciências Médicas da Universidade Sāo Francisco. Uma série de 22 questōes foram respondidas por alunos doprimeiro ano, 28 do terceiro e sexto anos. Os residentes receberam 32 questōes e os professores, 39 .

Foram distribuídos 210 questionários entre os professores e alunos que se encontravam no campus da Universidade, obtendose um retorno de $183(87 \%)$. Do total devolvido, 68 questionários 
pertenciam a alunos do primciro ano (91\% dos distribuídos), $45 \mathrm{do}$ terceiro ( $82 \%), 40$ do sexto $(80 \%), 6$ residentes $(75 \%)$ e 24 professores $(75 \%)$. Houvc entrevistados queomitiram uma ou outra resposta, sem que o fato comprometesse o trabalho. In felizmente, no momento do estudo, a instituição contava com poucos residentes. Os alunos do primeiro e terceiro anos tiveram nocurso de Sa úde \& Contexto uma introduçāo ao tema, com dramatizaçāo do mito de Asclépio c discussāo em grupo das dificuldades vivenciadas no curso de Anatomia.

\section{REFLEXŌES SOBRE OS DADOS COLETADOS}

Cento e trinta e dois entrevistados (72\%) responderam - bloco I, tabela 1 - quc lidar com a morte influenciou na escollha da profissão. A ponto de interferir responderam 9 (5\%); que não pesou nada, 51 $(28 \%)$ dos inquiridos. Chamou nossa atençāo a tendência de um aumento das respostas "nāo pesou nada", assinaladas por 13 (19\%) alunos do primeiro ano, $12(26 \%)$ do terceiro, $12(30 \%)$ do scxto, 3 $(50 \%)$ residentes c 11 (46\%) professores, à medida que o aluno se aproxima da prática e se torna umprofissional. Estariam os profissionais negando para atuarou foram privilegiados com um ensino que os preparou para lidar com a morte e o morrer? Deixcmos que as indagaçōes a segruir nos dêcm a resposta.

Nas questões de 2 a 5, bloco I, notamos que nossos alunos e professores vêm de uma cultura cm que negação e reserva são as formas de a família sc rclacionar com a mortc, sendo o assunto abordado com pouca freqüência em 112 (61\%) entrevistados e na medida do inevitável em $18(9,8 \%)$. Quarenta e scis $(26 \%)$ responderam que a família chegava a discutiro tema com freqüência. Oito (33\%) professores vêm de um ambiente familiar que discutia o assunto na medida do incvitável, o que revela uma negaçāo mais evidente que entrc os alunos, dentre os quais $26(16 \%)$ apontaram para a mesma alternativa, o que poderia trazer alguma dificuldade na relaçāo de aprendizado. Porém, devo reforçar o fato de os alunos do primeiro ano tcrem tido algum diálogo sobre o tema, o que poderia interferir em suas respostas. Apesar de nāo discutido, 159 (87\%) entrevistados responderam que a família nunca cscondcu a morte de familiarcs e amigos. Cento e sete (58\%) inquiridos participaram dos funcrais na infância e 75 (41\%) quase nunca ou nunca. No momento da pesquisa, 136 (74\%) entrevistados participam dos funerais e $46(25 \%)$ quasenunca ou nunca. Estaria a profissāo levando o individuo a uma melhor accitaçāo da morte ou a maior participaçāo no ritual ocorreria para se tentar compreender melhor a estranheza que a morte nos traz?

Nas questōes de 6 a 9, bloco I, 181 (99\%) inquiridos assinala- ram ser incvitável sentir a morte de um paciente e 104 (57\%) que isso nāo interferiria na atuaçāo profissional. Todos os professores responderam sentir, mas nāo deixava $m$ a dor interferir na profissāo. Entre os alunos, $40(21 \%)$ responderam que sentiriam a morte dependendo do caso. Vinte cdois (92\%) professores responderam que o óbito deveria ser comunicado pelo médico. O resultado não coincide com a obscrvaçāo de quem atua no Hospital Universitário - e mesmo cm outros locais de trabalho-, ondc esta responsabilidade é transferida para assistentes sociais, psicólogas, enfermeiras e residentes. Entre o dito e o praticado há uma distância que parece indicaruma defesa contra o sofrimento. Cento e vintc e scis (69\%) inquiridos sentiram-seincomodados em falar sobrc a morte. Apesar de 10 (41\%) professorcs responderem que o assunto pesquisado nāo incomoda nada, $19(79 \%)$ consideram ser muito importante a discussāo do tema no curso médico. P’ortanto, o tema incomoda e toma-sc nccessário um preparo na formaçāo acadêmica. Os residentes, $6(100 \%)$, talvez por conviverem em tempo integral com o sofrimento de seus pacientes ou estarem sob aval iaçāo - evitar ou negar podcria significar em suas fantasias uma reprovaçāo - , responderam que abordar o assunto incomodou.

Ao analisarmos as questōcs seguintes de 10 a 3B, blocos II e III, verificamos que $16(67 \%)$ professores afirmam que o tema nāo foi abordado em nenhuma disciplina durante sua formaçāo. Quandodiscutido, $2(25 \%)$ responderam que foi superficialmente. Apesar da experiência dos professores, $30(66 \%)$ alunos do terceiro ano acreditam que o assunto será abordado durante o curso e os 15 (34\%) que nāo crêem consideram importante a abordagem do assunto. Mas a realidade obtida nos anos seguintes de graduaçāo ć outra: ou o curso of creceu um pouco, mas não onecessário, ou não ofereceu nada. Éo que podemos concluir ao verificarmos que $33(82 \%)$ alunosdo último ano e $18(75 \%)$ professores responderam que a escola não cumpriu scu papel ao nāo ter oferecido mcios para o profissional lidar com a morte. A expectativa scrá mais uma vez frustrada pcla afirmaçāo de $2.3(96 \%)$ professores ao responderem que as revistas e os livros médicosnãopreenchem a necessidade acadêmica.

Pelas respostas das questões 20 a 22, quando $4(66 \%)$ residentes afirmam que os colegas e professores conversam, mas nāo o suficiente sobre a morte, c $9(37 \%)$ professores afirmam que conversam raramente ou nunca com os alunos, podemos concluir que a regra acadêmica, ao se falar da morte, ć osilêncio. Oproblema é agravado quando $29(79 \%)$ professores responderam que os colegas conversam raramente ou nunca sobre a morte. Mesmo cm casa, 11 (46\%) professores, em caso de perda na família, conversam, mas não o su ficiente com os familiares, 5 (21\%) conversam raramente c 1 (4\%) nāo conversa sobre a morte. Tristc ocorrência o fato de o ambiente de 
trabalhomédico nāoser diferente daquele dapopulaçāogeral, emque a negação ou evitação é a forma de defesa possivel. O problema éque o médico, em algum momento, terá de encarar a perda. Como nossos profissionais estarāo resolvendo o vácuo deixado no ensino enos livros? O que faz com que $17(70 \%)$ professores afirmem que a profissāo melhorou sua relaçāo com a morte, se negar é a regra no ambiente de trabalho e 11 (45\%) nāo doaram seus órgāos por não se sentirem preparados ou não terem pensadona própria morte? Quando nem Deus preenche o vazio, quais serāo os rumos das defesas? Abandonar a profissāo? Não, pelo menospara $18(75 \%)$ professores c $3(50 \%)$ residentes, mesmo com 16 (64\%) professores, $5(83 \%)$ residentes e 25 (63\%) alunos do último ano respondendo que experimentam a sensaçāo de impotência ao perderem um paciente. Parece-nos, pelas respostas de residentes e professores, que a afirmaçāo de $30(66 \%)$ alunos do terceiro ano de que lidariam naturalmente ou com poucadificuldade com a primeira morteé mais um desejo que uma realidade, pelo menos enquanto perdurar a negaçãono ambiente universitário.

$\mathrm{Na}$ análise das a firmaçōes de Royo e Ariosto, tabelas 1Be 2B, frente a um paciente terminal que solicita ao médico todo o esforço para mantê-lo vivo, 16 (67\%) professores e $3(50 \%)$ residentes afirmam que respeitariam o pedido e nenhum aceleraria a morte; 7 (29\%) professores concordariam em termos e nada fariam que prolongasse a vida e o sofrimento, e nenhum residente ou professor apressariama morte. Caso o paciente solicitasse o término do sofirimento, 9(38\%) professores e $1(16 \%)$ residente nāo respeitariam opedido e fariam todo o possivel para mantê-lo vivo; 9 (38\%) professores e 4 (66\%) residentes concordariam em termos enada fariam que prolongasse a vida e o sofrimento, e 2 (8\%) professores acelerariam sua morte. Portanto, a tendência dos profissionais é nāo aceitar a cutanásia, respeitando-sea vontade do paciente em termos. Quando a solicitação é para acabar com o sofrimento, $38 \%$ dos professores fariam todo o possivel para mantê-lo vivo.

Nas questōes sobre textos literários, bloco IV, a sensação de ausência torna-se evidente como sentimento de perda em 126 (69\%) entrevistados, havendo urna certa tendência, em 4 (17\%) professores, a negar a sensaçāo quando comparados com residentes. Cento e dezenove (65\%) inquiridos consideram que a sensação de ausência é uma forma satisfatória de reação ante a perda, e 43 (23\%) consideram uma resposta inadequada. Nãoseria fonte de preocupação a percentagem de alunos e profissionais que consideram uma reaçāo própria do processo de luto como algo anormal e inadequado? Cento e sessenta e um (88\%) entrevistados responderam que a necessidade de acreditar na imortalidade é freqüente entre os ho- mens. Cento e setenta (98\%) inquiridos concordam com a necessidade de o médico encontrar formas de se relacionar com a morte, c 111 (60\%), que o suicídio entre os médicos tem tudo ou muito a ver com a sensaçāo de impotência. Setenta e dois (40\%) entrevistados acham que tem pouco ou nada a ver.

Na tabela $1 \mathrm{C}$, bloco $\mathrm{V}$, os professores associaram à morte as palavras passagem, saudade, ausência e inevitável -29 (66\%) das 44 respostas; os sextanistas, tristeza c fim- 42 (61\%) das 69 respostas; os alunos doprimeiro e segundoanos tenderam mais para as palavras dos grupos I e II - 46 (35\%) e 55 ( $42 \%)$, respectivamente, para o primeiro ano, e $33(43 \%)$ e $32(42 \%)$, respectivamente, para o segundo. Das respostas dadas pelos residentes, $5(42 \%)$, corresponderam às palavras dogrupo I. No conjunto, foram utilizadas com mais freqüência as palavras firn, tristeza, perda, saudade, passagem, ausência, inevitável, mudança, liberdade e início.

Na tabela $2 \mathrm{C}$, as palavras mais utilizadas por todos os grupos para definir a vida foram alegria, amor esaúde. Nota-se uma tendência nos alunos doprimeiro, terceiro eresidentes a responderem dificuldade esofrimento. Quanto ao sentimento experimentado ao responder ao questionário, verificamos na tabela $3 \mathrm{C}$ que $10(55 \%)$ das respostas dos residentes e 43 (46\%) das respostas dos alunos do sexto ano foram angústia, tristeza e medo, diferentemente dos outros grupos, nos quais as palavras mais utilizadas foram reflexāo, interesse, angústia, curiosidade, tristeza, satisfaçāo e dúvida.

A tabela 4C nos mostra comoa academia está perdida em definir dequem seria a responsabilidade do ensino sobre a morte. Enquanto os alunos dos primeiros anos responderam que a I'sicologia seria a responsável por abordar o assunto, alunos de último ano, residentes eprofessoresperdem-se num leque de opçōes.

\section{CONCLUSÃO}

Não existe nada, desde os primórdios de nossa civilizaçāo, que nos traga mais desyosto e aflição do quea morte. P'ortanto, não énada atual a dificuldade de ohomem lidar com a morte e o morrer. Os primeiros cultos aos mortos de que temos registroapresentam indícios dessa angústia. Com a morte, vai-se a fantasia da imortalidade, fica somente a lembrança, que o tempo se encarregará de apagar.

Na mitologia, Asclépio, desafiando os deuses, ressuscita um morto. Um raio c uma passagem pelo inferno são o castigo recebido por sua petulância. Mudanças ocorreram nas formas de ohomem lidar com a perda ao longo dos séculos. Em Dante, temos uma visão continuísta da morte, com o morto chegando aoparaíso com emoçōes e estrutura física humanas; a Igreja crê na existência de 
um estado espiritual que responsabiliza o abandono da vida religiosa pela infelicidade do homem moderno e há os que mantêm uma descrença absoluta quanto à possibilidade da existência de alguma outra forma de vida.

Em épocas recentes, o avanço científico e teconológico vêm levando a sociedade a transformaçōes nunca experimentadas. Ocapitalismo acoplado ao consumoassocia-se na modemidade à dessacralizaçāo dohomem. Apexar detudo, a morte, quandomuito, podeser maquiada, mas nunca evitada ou trocada por moeda corrente. Podemos fazer dela um espetáculo nas telas das TVs ou dos cinemas, mas um dia cla estará bem diante de nosso nariz, e as imagens e sinais se transformarāo na realidade nua e crua.

Ante presença tāo assustadora, é natural agirmos como se a morte nāo existisse. Impulsionados para a autoconservaçāo, vemos a morte no vizinho, nas ruas, nas vielas sujas e escuras, nunca em nós. Omedo deperder o próprio culeva o homem moderno a acreditar que sua ciência poderá vencê-la. Ninguém discutirá os avanços alcançados no século que termina, mas também houve uma mudança do processo do morrer $\mathrm{c}$, muitas vezes, o homem perdeu o direito a uma morte tranqüila, ficando à mercê da máquina e de quem a domina. $\mathrm{E}$ como estará a formaçāo e a saúde daqueles que deverāo zelar pela vida? Imaginar que no caso dos médicos existe um preparo prévio quc os habilita a enfrentar a morte é nāo conhecer os curriculos de ensino médico. Os médicos sempre se depararam com a morte, mas poucos foram os momen tos de reflexāo sobre sua atuaçāo perante ela. Este trabalho tenta retirar da obscuridadeos verdadeiros papéis exercidos pelas instituiçōes cuja atribuiçāoé o ensino médico e o perfil de seus atores: professores, residentes e alunos. A academia estaria contemplando as expectativas dosmembros que a compöem?

Descobrimos, entāo, que a comunidade acadêmica tem consciência de suas limitaçōes e dificuldades, sabe que a sociedade e a escola nāo lhe oferece oportunidade para discutir o assunto e deseja tê-lo mais abordado durante o curso médico. A esperança, entre os alunos dos primeiros anos, de que o currículo venha suprir tal deficiência é frustrada quandochegam nos últimos anos. Pior, nem os livros e revistas médicas tratam doassunto. Os professores nāo se sentem preparados, nāo conversando nem entre eles sobre a morte. Existe uma clara tendência à evitaçāo e negaçāo no ambiente profissional que é transferida ao ensino. A expectativa é de que os médicos aprendam a conviver com o morrer, mas é unânime a opiniāo de que os alunos saem da faculdade sem aprender a lidar satisfatoriamente com o processo.

O profissional passa mal ao perder um paciente e acredita quea sensaçāo de ausĉncia é uma forma satisfatória de reaçāo à morte.
Sente-se impotente c gostaria de poder fazer mais, alguns inclusive chegarama pensar emabandonar a profissāo. Aomesmo tempo em que aceitam o desígnio de Deus, algo relacionado com a impotência, uma parcela dos entrevistados apresenta certa tendência à onipotência em suas açōes, conforme podemos observar nas questōes relacionadas com as afirmaçōes de Royoe Ariosto ${ }^{21}$. Uma parcela nada desprezivel de professores ealunos de sextoano considera o sentimento de ausência uma reaçāo inadequada e anormal, coisa de poeta. Com certeza, éprexcupante o fato dese achar anormal algo que faz parte do processo de luto, carregado de uma negaçāo absoluta da dor. Se ela nāoé canalizada de forma adequada, como estarāo respondendo estes profissionais à frustraçāo da perda?

A morte sempre nos traz o sentimento de perda, fime ausência, passagem e mistério, dor emedo, independentemente da experiência do individuo com a morte. Os dados indicam, inclusive, que quanto mais experiência, mais freqüente osentimento de mistério, ausência e passagem, conforme podemos observar entre os professores. Responder o questionário aproxima sentimentos de reflexāo, benefício e harmonia; também de lealdade, naturalidade e a tençāo. Existe alguém, por trás do questionário, que tenta ser atencioso e leal. Mas falar sobre a morte também trazo sofrimento e o medo.

Sexo e morte sāo assuntos que parecem nāo pertencer à classe médica. De fato, pertencem à toda a humanidade, devem ser discutidos por leigos, artistas, antropólogos, biólogos, filósofos, coveiros, etc. Nāo há mais espaço para omissōes, e toda a academia deve procurar caminhos para solucionar o problema.

\section{AGRADECIMENTOS}

O autor reconhece e agradece a contribuiçāo dos professores Dr. Enesto Jacob Keim, educador, pelas sugestōes na elaboraçāodo questionário, Claudionor Picarelli, do Departamento de Psiquiatria, pela leitura e sugestōes, e Ms. Luiz. Fiorelli, cujo esforço permitiu uma amostragem representativa para a conclusāo do trabalho.

\section{REFERÊNCIAS BIBLIOGRÁFICAS}

1. ROSA, C. A. P. Mortalis: Os médicos e a morte In: Temas de Bioética. Cademos do IFAN-USF,Sāo Paulo, v. 10, n. 1, p. 63 90, 1995.

2. ROSA, C. A. P. Mortalis: Os médicos e a morte. Sāo Paulo: Editora Cone Sul, 1997.

3. ROSA, C. A. P. O médico e a morte. Medicina-USF, Sāo Paulo, v. 12, n.2, p. 73-76, 1994. 
4. KÜBLER-ROSS, E. Pcrguntas e respostas sobre a morte e o morrer. Sāo Paulo: Martins Fontes, 1979.

5. MCFARLAND, K. F et al. Dealing with death and dying. Medical Education, Oxford, v. 28, n.2, p 136-138, Mar. 1994.

6. FEIGENBERG, I.. Terminal care. Apud: Torres, W. C.; Guedes, W.G. O psicólogo e a terminalidade. Arquivos Brasileiros de Psicologia, v.39, p. 29-38, 1987.

7. M $\triangle S L O W, A . I$. The psychology of science. Apud: Torres, W. C.; Guedes, W.G. Opsicólogo ea terminalidade. Arquivos Brasileiros de Psicologia, Rio de Janeiro, v. 39, n. 2, p. 29-38, Abr. 1987.

8. MERMANN, A. C. Spiritual aspects of death and dying. The Yale Journal of Biology and Medicine, Yalc, v. 65, n. 2, p. 127-142, 1992.

9. FREUD, SIGMUND. Obras Completas. Madrid: Editorial Biblioteca Nueva, 1967.

10. FREUD, SIGMUNND. Sinopses da standard edition da obra psicológica completa. Madrid: Editora Salamandra, 1979.

11. ROSA, C. A. P. Erro médico e condiçōes de trabalho Psicopatologia e condiçōes de trabalho no erro médico. Medicina-USF, São Paulo, v. 13, n. 1, p. 43-64, 1995.

12. FIELLD, D. Education for palliative care: formal education about death, dying and bereavement in UK medical schools in 1983 and 1994. Medical Education, Oxford, v. 29, n. 6, p. 414-419, Nov.1995.

13. BOEMER, M. R. etal. O tema morte: uma proposta de educação. Revista Gaúcha de Ėnfermagem, Porto Alegrc, v. 12, n. 1, p. 26-32, Jan. 1991.

14. BOEMER, M. R. et al. Dimensão pedaýónica do tema "morte". Educación Médica y Salud, v. 26, n. 3, p. 430-443, Jul. 1992

15. Physicians for the Twenty-first Century: Report of the panel on the general and professional education of the physician and college preparation for medicine. Association of $\Lambda$ merican Medical Colleges. Apud: Boemer. M.R. etal. Dimensāo pedagógica do tema "morte". Educación Médica y Salud, v. 26, n. 3, p. 430-443, Jul. 1992

16. DURAND, R.P. et al. Family physicians attitudes toward death and the terminally-ill patient. Family Practice Research Joumal, v. 9 , p. 123-129, 1990.

17. MARTINS, J. S. A morte e os mortos na sociedadebrasileira. São Paulo: Hucited, 1983.
18. D’ASSUMPÇÃO, E. A. Tanatologia - A assistência aos doentes terminais - Uma nova especialidade médico-psicológica. Folha Médica, v. 98, n. 2, p. 29-36, Jan. 1989.

19. D`^SSUMPÇĀO, E. ^. Perfil da atitude médica diante do paciente terminal. Revista Brasileira Cirurgia, v. 84, n. 4, p. 159162, Jul. 1994.

20. CASSORLA, M. S. O mito de Asclépio e o médico lidando com a mortc. In: Temas de Bioética. Cadernos do IFAN - USF, São Paulo, v.10, n. 1, p. 51-62, 1995.

21. $\Lambda$ SÚ $\Lambda$, J. El nuevo derecho penal, liberdad de amar y derecho a morir. Madrid: Editora I-Iistoria Nueva, 1928.

Endereço para correspondência

Av. Lucas de Siqueira Franco, 196 12940-000 - Atibaia - SP - Brasil

E-mail:meiotom@opus.com.br

\section{QUESTIONÁRIO APLICADO}

BLOCO I (Questōes respondidas por toda a população estudada)

1) O fato de o médico ter de lidar com a morte pesou em sua decisão deescolher a profissão? A) Pesou muito, a ponto de interferir na decisāo; B) P'csou, mas nāo a ponto de interferir na decisāo; C) Pesoupouco; D) Nāopesou nada

2) Na familia ou na escola o tema morte era abordado: A) Com freqüência e com naturalidade; B) Com pouca freqüência e com naturalidadc; C) Com pouca freqüência c com reservas; D) Era abordado apenas na medida do inevitável

3) Com relaçāo às mortes: A) Sua família nunca escondeu das crianças a morte de familiares, amigos eanimais domésticos; B) Sua família escondeu das crianças a morte de familiares c amigos; C) Sua família escondeudas criançasa morte de animais domésticos; D) Sua família escondeu sempre a morte de familiares, amigose animais domésticos

4) Quando criança você participou dos funerais de parentes e amigos: A) Sempre; B) A maioria das vezes; C) Quase nunca; D) Nunca

5) Hoje, você participa dos funcrais de parentes e amigos: $\Lambda$ ) Sempre; B) A maioria das vezes; C) Quase nunca; D) Nunca 
6) Qual seria sua reaçāo comoum médico que perdeu um pacientc? A) Sentiria a morte sempre que ocorresse; B) Sentiria, mas sem que isso interferisse na profissão; C) Sentiria conforme o caso; D) Nunca sentiria a morte dopaciente

7) Na sua opiniāo, quem deve avisar os familiaressobre a morte de um paciente: A) $\mathrm{O}$ assistente social; B) A enfermagem; C) A direção do hospital; D) Opróprio médico

8) Você considera a discussāo da morte no curso médico: A) Muito importante; B) Apenas importante; C) Pouco importante; D) Desnecessária

9) Falar sobre a morte: A) Incomoda muito; B) Incomoda um pouco; C) Incomoda muito pouco; D) Não incomoda nada

BLOCO II (Questões respondidas pelos alunos do $3^{\circ}$ e $6^{\mathrm{g}}$ anos, residentes e médicos)

10) Alguma matéria do seu curso preocupou-se com o tema "morte"? A) Sim; B) Nāo

11) Em caso afirmativo, o tema foi discutido: A) Commuita profundidade; B) Suficientemente; C) Superficia Imente; D) Nāo foi discutido

\section{BLOCO III (Questões para grupos específicos)}

12) De acordo com a sua opiniāo, qual matéria deveria tratar deste assunto no 3" ano? A) Psicologia; B) Patologia; C) Disciplinas clíricas; D) Propedêutica médica

13) Você acredita que durante o restante do curso o assunto ainda scrá abordado? A) Acho que sime considero muito importante; B) Acho que sim c nāo considero importante; C) Acho que nāo, mas considero muito importante; D) Acho que nāo e considero pouco importante

14) O cursode Medicina ofereceu-lhe meios de lidar com a morte? A) Ofereceu todos os meios; B) Ofereccu o necessário; C) Ofereccu um pouco, mas nāo o necessário; D) Nāo ofereccu nada

15) Em sua opiniāo, os livrose as revistas médicas: A) Discutem abertamente o tema; B) Discutem o necessário; C) Discutem muito pouco; D) Nāo discutem nada

16) Você, como médico inuciante: A) Lidaria na turalmente com sua primeira morte; B) Teria um pouco de dificuldade para lidar com sua primeira morte; C) Teria muita dificuldade para lidar com sua primeira morte; D) Nāo saberia o que fazer
17) Quando um paciente morre em suas māos, você: A) Sente-se muito mal e não conversa sobre o assunto; $B$ ) Sente-se muito mal e procura conversar sobre oassunto; C) Sente-se mal e procura esquecer rapidamente o oconido; D) Não sente nada

18) Que sensação você experimenta ao perder um paciente: $A$ ) Sensaçāo de impotência, e acha quepoderia fazer mais; B) Sensaçāo de impotência, mas aceita a limitação; C) Sensaçāo de raiva por nāo poder fazer mais; D) Sensaçāo de raiva, mas aceita a limitaçāo

19) Por causa da morte, vocêjá pensou em abandonar a Medicina? A) Muitas vezes; B) Algumasvezes; C) Poucas vezes; D) Nunca

20) Os colegas mais velhos e professores conversam com você sobre o assunto? A) Conversam muito; B) Conversam, mas nāo o suficiente; C) Conversam raramente; D) Nunca conversam sobre o assunto

21) Você procura conversar com alunos c residentes sobre a morte? A) Conversa muito; B) Conversa, mas nāo o suficiente; C) Conversa raramente; D) Nunca conversa sobre o assunto

22) Você acha que os colegas: A) Conversam muito sobre o assunto; B) Conversam, mas nāo o suficiente; C) Conversam raramente; D) Nunca conversam sobre o assunto

23) Ena familia, em caso de perda de um parente próximo, você: A) Conversa muito sobrca morte; B) Conversa, mas nāo o suficiente sobre a morte; C) Conversa raramente sobre a morte; D) Nãoconversa sobre a morte

24) Vocêacha quc a profissão fez com que melhorasse sua relaçāo com a morte? A) Sim; B) Nāo

25) Como você vê Deus diante da morte de um paciente: A) Nada tem a ver; B) Revolto-me con tra Deus; C) Aceito como um desígnio deDeus;D) Nāo misturo minha fé com meu trabalho

Royo-Villanova y Morales: "Para mim, que sou um otimista, a vida, por pior que seja, ésempre a vida; prefiro viver tarado com todos os estigmas, saturado de mil enfermidades, coberto de todos os opróbrios... a nāo viver".

1B) Sc Royo fosse seu paciente e estivesse em fase final de carcinomatose: A) Você respeitaria o direito dele e faria tudo para mantê-lo vivo, mesmo se isso prolongasse o sofrimento dele; $B$ ) Você respeitaria odireito dele em termos, nada faria que prolongasse a vida e o sofrimento delc; C) Você nāo respeitaria o direito dele e aceleraria a morte

Ariosto Licurzi, In: "O Direito de Matar", 1934: "A uiltima vitória da medicina - frente à sua impotência cientifica - quandó 
impossivel triunfar sobre o mal incurável, será adormecer o agonizante na tranqüila sonolência medicamentosa que leva ao letargo eà morte total, suavemente.

2B) Se Ariosto fosse seu paciente e estivesse em fase final ce carcinoma tose: A) Vocênão respeitaria odireito delee faria tudo para mantê-lo vivo, mesmo seisso prolongasse o sofrimento dele; B) Você respeitaria o direito dele em termos, nada fariaque prolongasse a vida e o sofrimento dele; C) Você respeitaria o direito dele e aceleraria a morte

3B) Você doou seus órgãos:A) Sim; B) Não

4B) Não doou por: A) Não ter pensado na morte; B) Não estar preparado para tal

\section{BLOCO IV (Questōes sobre textos literários)}

Manuel Bandeira assim seexpressouao saber da mortedoamigo Mário de Andradeneste fragmento do poema "A Mário de Andrace Ausente":

Mas agora não sinto sua falta. \(Éscmpre assim quando o ausente \Partiu sem se despedir:\Vocênão se despediu.)\Vocênão morrcu: ausentou-se. $\backslash$ Direi: Faz tempoque ele não escreve. \Irei a São Paulo: vacênāo virá ao meu hotel. \Imaginarei: Está na chacrinha de São Roque. \Saberei que não, vocêausentou-se. Pra outra vida?! $A$ vida é uma só. A sua vida continua $\backslash$ Na vida que você viveu. $\backslash$ Por isso não sinto agora a sua falta.

1A) Você tem essa sensação de ausência ante a morte: A) Sempre; B) A maioria das vezes; C) Poucas vezes; D) Nunca

2A) Você considera essa sensação de ausência ante a morte: $A$ ) Uma forma satisfatória de reação; B) Uma forma freqüentee anormal de reação; C) Uma forma freqüentee inadequada de reação; D) Uma forma infreqüente e inadequada dereação

A sensibilidade de Murilo Mendes permitiu que ele se referisse ao disfarce em "Ante um Cadáver":

Quandoabandonaremosa parte inútil e decoratival do nosso scr?\Quando nos aproximaremos com fervor da nossa essência, \ Partindo nosso pobre pão com o Hóspede \Que está no céu e está próximo a nós? \ Para que esperar a morte a fim de nos conhecermos... \Éem vida que devemosnos apresentar a nós mesmos. $\$ Ainda agora essas coroas, esses letreiros, essas flores $\backslash$ Impedem de se vero morto na verdade. I Estendam numa prancha o homem nue definitivo $\backslash$ Eorestituam enfimà sua prometida solidāo.

3A) Você acha que o médico: A) Aprende a conviver com a morte; B) Nega a morte para conseguir conviver com ela; C) Consegue sair da faculdade em condições de lidar satisfatoriamente com a morte; D) Nunca aprende a conviver com a morte

4A)Essa necessidade de acreditar na imortalidade: A)É muito freqüente entre os homens; $B$ ) É freqüente entre os homens; $C$ ) $E$ pouco freqüente entre os homens; D) Nunca ocorre entre os homens

5A) Assinale as alternativas com que você concorda: A) Para poderem atuar de uma forma amadurecida, torna-senecessárioque os médicos desenvolvam formas de se relacionar com a morte; B) É desnecessário que os médicos se preocupem com a morte em sua formação;C) Quemnão está preparado para enfrentar a morte deve escollher outra profissão; D) Omédico deve se preocupar com a vidae não com a morte, já que é um privilégio do médico conviver com a morte

6A) Para você, a freqüência de suicidios entre os médicos: A) Tem tudo a ver com a sensação de impotência antea morte; B) Tem muitoa ver com a sensação de impotência antea morte; $C$ ) Tem pouco a ver com a sensação de impotência ante a morte; D) Não tem a ver com a sensação de impotência ante a morte

\section{BI_OCO V (Questões abertas)}

1C. Escreva duas palavras que sintonizem sua visão da morte:

2C. Escreva três palavras que expressem um conceito em sua comunidade sobreo significado da vida:

3C. Escreva três palavras sobre o sentimento que você experimentou ao responder este questionário:

4C. Cite duas disciplinas de $1^{\prime \prime} \mathrm{e} 2^{\circ}$ ano que deveriam privilegiar a morte como tema de estudo: 


\section{TABELAS}

\section{Bloco I}

Tabela 1 - O fato de o médico ter de lidar com a morte pesou em sua escolha profissional:

\begin{tabular}{|c|c|c|c|c|c|}
\hline & $\begin{array}{l}1^{\circ} \text { Ano } \\
N^{(10}-(3)\end{array}$ & $\begin{array}{l}3^{\prime \prime} \text { Ano } \\
N^{\prime \prime}-\%\end{array}$ & $\begin{array}{l}6^{\prime \prime} \text { Ano } \\
N^{n}-\%\end{array}$ & $\begin{array}{c}\text { Residentes } \\
\mathrm{N}^{\prime \prime}-\%\end{array}$ & $\begin{array}{c}\text { Professores } \\
N^{\prime \prime}-1 / \%\end{array}$ \\
\hline a) Muito, a ponto de interferir & $3-5$ & $3-7$ & $1-2,5$ & $1-16,5$ & $1-4$ \\
\hline b) Pesou, mas nảo a ponto de interferir & $31-46$ & $22-49$ & $22-55$ & $1-16,5$ & $8-.3 .3$ \\
\hline c) I'esou pouco & $21-.30$ & $8-18$ & $5-12,5$ & $1-16,5$ & $4-16$ \\
\hline d) Não pesou nada & $1.3-19$ & $12-26$ & $12-30$ & $3-50$ & $11-46$ \\
\hline
\end{tabular}

Tabela 2 - Na família ou na escola o tema morte era abordado:

\begin{tabular}{|c|c|c|c|c|c|}
\hline & $\begin{array}{l}\text { T"Tno } \\
N^{\prime \prime}-(\%)\end{array}$ & $\begin{array}{l}3 \times T n \\
N^{\prime \prime}-(")\end{array}$ & $\begin{array}{l}6 \text { Ano } \\
N^{\prime \prime}-\%\end{array}$ & $\begin{array}{c}\text { Residentes } \\
N^{\prime \prime}-\%\end{array}$ & $\begin{array}{c}\text { Prolessores } \\
N^{1 \prime \prime}-1 / 1 / 3\end{array}$ \\
\hline a) Com lreqüe & $18-26$ & $1.3-29$ & $10-25$ & $1-16,5$ & $4-16$ \\
\hline b) Com pouca freguencia e naturalidade & $27-40$ & $15-33$ & $19-47,5$ & $3-50$ & $9-38$ \\
\hline c) Com pouca freçuência e reservas & $20-29$ & $9-20$ & $6-15$ & $1-16,5$ & $3-1.3$ \\
\hline d) Abordado apenas na medida do inevitável & $3-5$ & $18-18$ & $5-12,5$ & $1-16,5$ & $8-3.3$ \\
\hline
\end{tabular}

Tabela 3 - Com relação às mortes de familiares, amigos e animais domésticos, sua fa múlia:

\begin{tabular}{|c|c|c|c|c|c|}
\hline & $\begin{array}{l}1 \text { Ano } \\
N^{\prime \prime}-(1 / \%\end{array}$ & $\begin{array}{l}3 \text { Ano } \\
N^{\prime \prime}-1 / \%\end{array}$ & $\begin{array}{l}6^{\prime \prime} \text { Ano } \\
N^{\prime \prime}-\%\end{array}$ & $\begin{array}{c}\text { Residentes } \\
N^{\prime \prime}-\%\end{array}$ & $\begin{array}{c}\text { Professores } \\
N^{\prime \prime}-\%\end{array}$ \\
\hline a) Nunca escondeu das crianças & $57-84$ & $39-87$ & $36-90$ & $6-100$ & $21-88$ \\
\hline b) Escondeu a morte de familiares e amigos & $7-10$ & $3-7$ & $2-5$ & $0-0$ & $2-8$ \\
\hline c) Escondeu a morte de animais domésticos & $4-6$ & $2-4$ & $2-5$ & $0-0$ & $1-4$ \\
\hline d) Escondeu sempre das crianças & $0-0$ & $1-2$ & $0-0$ & $0-0$ & $0-0$ \\
\hline
\end{tabular}

Tabela 4-Quando criança, você participou dos funerais de parentes e amigos:

\begin{tabular}{|c|c|c|c|c|c|}
\hline & $\begin{array}{l}1^{\prime \prime} \text { Ano } \\
N^{\prime \prime \prime}-x_{1}\end{array}$ & $\begin{array}{l}3 \text { Ano } \\
N^{n}-1 / \%\end{array}$ & $\begin{array}{l}6 \text { Ano } \\
N^{0}-\% / \%\end{array}$ & $\begin{array}{c}\text { Residentes } \\
N^{\prime \prime}-\%\end{array}$ & $\begin{array}{c}\text { Prolessores } \\
N^{\prime \prime}-\%\end{array}$ \\
\hline a) Sempre & $8-12$ & $10-7$ & $7-17,5$ & $1-16,5$ & $4-16$ \\
\hline b) A maioria das vezes & $32-47$ & $12-27$ & $20-50$ & $3-50$ & $10-42$ \\
\hline c) Quase nunca & $15-22$ & $15-.3 .3$ & $10-25$ & $2-3.3$ & $9-.38$ \\
\hline d) Nunca & $1.3-19$ & $7-16$ & $3-7,5$ & $0-0$ & $1-4$ \\
\hline
\end{tabular}

Tabela 5 - Hoje, você participa dos funerais de parentes e amigos:

\begin{tabular}{|c|c|c|c|c|c|}
\hline & $\begin{array}{l}1 . \text { Ano } \\
N^{\prime \prime}-\left({ }^{\prime}\right)\end{array}$ & $\begin{array}{l}3^{\prime \prime} \text { Ano } \\
N^{\prime \prime}-(\%)\end{array}$ & $\begin{array}{l}6^{\prime \prime} \text { Ano } \\
\mathrm{N}^{\prime \prime \prime}-\%\end{array}$ & $\begin{array}{c}\text { Residentes } \\
N^{*}-\%^{\prime}\end{array}$ & $\begin{array}{c}\text { Professores } \\
N^{\prime \prime}-\%\end{array}$ \\
\hline a) Sempre & $17-25$ & $17-22$ & $10-25$ & $1-16,5$ & $3-1.3$ \\
\hline b) $\wedge$ maioria das vezes & $29-4.3$ & $20-44$ & $21-52,5$ & $3-50$ & $15-6.3$ \\
\hline c) Quase nunca & $16-24$ & $6-1.3$ & $8-20$ & $2-.33$ & $6-24$ \\
\hline d) Nunca & $5-8$ & $2-5$ & $1-2.5$ & $0-0$ & $0-0$ \\
\hline
\end{tabular}

Tabela 6 - Qual seria sua reação como médico que perdeu um paciente $\left(1^{\circ}, 2^{\circ}, 6^{\circ}\right.$ e residentes): Como vocé acha que deve se portar um médico que perdeu um paciente (professores):

\begin{tabular}{|c|c|c|c|c|c|}
\hline & $\begin{array}{l}l^{\prime \prime} \text { Ano } \\
N^{\prime \prime \prime}-(" /)\end{array}$ & $\begin{array}{l}3^{\circ} \text { Ano } \\
N^{\circ}-\%\end{array}$ & $\begin{array}{l}\sigma^{\prime \prime} \overline{\lambda o} \\
N^{\prime \prime}-\%\end{array}$ & $\begin{array}{c}\text { Residentes } \\
N^{0}-{ }^{\prime} \%\end{array}$ & $\begin{array}{c}\text { Professores } \\
N^{*}-1 \%\end{array}$ \\
\hline a) Sentiria a morle sempre que ocorresse & $14-21$ & $\overline{15-.3 .3}$ & $7-17,5$ & $0-0$ & $0-0$ \\
\hline b) Sentiria, mas sem deixar inlerterir & $33-49$ & $20-44$ & $22-55$ & $5-8.3$ & $24-100$ \\
\hline c) Sentiria conforme o caso & $21-30$ & $9-20$ & $10-25$ & $I-16,5$ & $0-0$ \\
\hline d) Nunca sentiria a morte & $0-0$ & $1-2$ & $1-2,5$ & $0-0$ & $0-0$ \\
\hline
\end{tabular}


Tabela 7 - Na sua opinião, quem deve avisar os familiares sobre a morte de um paciente:

\begin{tabular}{lccccc} 
& $\mathrm{I}^{\prime \prime}$ Ano & $3^{\prime \prime}$ Ano & $6^{\circ}$ Ano & Residentes & Professores \\
& $\mathrm{N}^{\prime \prime}-\%$ & $\mathrm{~N}^{\prime}-\%$ & $\mathrm{~N}^{\prime \prime}-\%$ & $\mathrm{~N}^{\prime \prime}-\%$ & $\mathrm{~N}^{\prime \prime}-\%$ \\
\hline a) Assistente social & $4-6$ & $3-7$ & $1-12,5$ & $0-0$ & $2-8$ \\
b) Enfermagem & $1-1$ & $1-2$ & $1-2,5$ & $0-0$ & $0-0$ \\
c) Direça do hosjital & $1-1$ & $1-2$ & $0-0$ & $0-0$ & $0-0$ \\
d) O próprio mídico & $62-92$ & $39-87$ & $38-95$ & $6-100$ & $22-92$ \\
\hline
\end{tabular}

Tabela 8 - Você considera a discussão da morte no curso médico:

\begin{tabular}{|c|c|c|c|c|c|}
\hline & 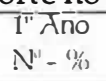 & $\begin{array}{l}3^{3} \text { Tno } \\
N^{*}-\%\end{array}$ & $\begin{array}{l}\text { क्षा० } \\
N^{\prime \prime}-\%\end{array}$ & $\begin{array}{l}\text { Kesidentes } \\
\mathrm{N}^{\prime \prime \prime}-1 / 1\end{array}$ & $\begin{array}{c}\text { Professores } \\
N^{\prime \prime \prime}-\%\end{array}$ \\
\hline a) Muito importarte & $51-75$ & $36-80$ & $.31-77.5$ & $3-50$ & $19-79$ \\
\hline b) Apenas importante & $17-25$ & $9-20$ & $9-22,5$ & $3-50$ & $5-21$ \\
\hline c) l'ouco importante: & $0-0$ & $0-0$ & $0-0$ & $0-0$ & $0-0$ \\
\hline d) Desnecessária & $0-0$ & $0-0$ & $0-0$ & $0-0$ & $0-0$ \\
\hline
\end{tabular}

Tabela 9 - Falar sobre a morte:

\begin{tabular}{|c|c|c|c|c|c|}
\hline & $\begin{array}{l}T^{\prime \prime} \text { Ano } \\
N^{N}-1 / 1 / 1\end{array}$ & $\begin{array}{l}3^{\prime \prime} \lambda \text { no } \\
N^{\prime \prime}-(\%)\end{array}$ & 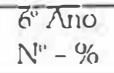 & $\frac{\text { Residentes }}{N^{\prime \prime}-\%}$ & $\begin{array}{c}\text { Professores } \\
N^{\prime \prime}-\%\end{array}$ \\
\hline a) Incomoda muito & $3-4$ & 716 & $3-7.5$ & $1-16,5$ & $3-1.3$ \\
\hline b) Incomoda um pouco & $27-40$ & $18-40$ & $21-52,5$ & $5-83$ & $8-3.3$ \\
\hline c) Incomoda muito pouco & $15-22$ & $6-13$ & $6-15$ & $0-0$ & $3-1.3$ \\
\hline d) Não incomoda nada & $23-.34$ & $14-31$ & $10-25$ & $0-0$ & $10-41$ \\
\hline
\end{tabular}

Bloco II

Tabela 10 - Alguma matéria do curso preocupou-se com o tema "morte":

\begin{tabular}{|c|c|c|c|c|}
\hline & $\begin{array}{l}3 \text { Ano } \\
\mathrm{N}^{\prime \prime}-\%\end{array}$ & $\begin{array}{l}6 / \mathrm{dno} \\
\mathrm{N}^{\prime \prime}-6 / 1\end{array}$ & $\begin{array}{c}\text { Residentes } \\
N^{\prime \prime}-\%\end{array}$ & $\begin{array}{c}\text { Prolessores } \\
N^{\prime \prime}-1 / \%\end{array}$ \\
\hline a) Sim & $35-58$ & $16-40$ & $4-66,5$ & $8-3.3$ \\
\hline b) Nà̃o & $10-22$ & $24-(6)$ & $2-3.3,5$ & $16-67$ \\
\hline
\end{tabular}

Tabela 11 - Em caso a firmativo, o tema foi discutido:

\begin{tabular}{|c|c|c|c|c|}
\hline & $\begin{array}{l}3 \text { तno } \\
N^{*}-\%\end{array}$ & $\begin{array}{l}\text { E तno } \\
N^{\prime \prime}-\%\end{array}$ & $\begin{array}{l}\text { Residentes } \\
N^{\prime \prime}-6 \%\end{array}$ & $\begin{array}{c}\text { Prolessores } \\
N^{\prime \prime}-\%\end{array}$ \\
\hline a) Com muita prozundichacte. & $2-6$ & $0-0$ & $0-0$ & $1-13$ \\
\hline b) Suficientemente & $10-28$ & $5-.31$ & $2-50$ & $5-62$ \\
\hline c) Superficialment: & $2.3-66$ & $11-69$ & $2-50$ & $2-25$ \\
\hline d) Não foi discutito & $0-0$ & $0-0$ & $0-0$ & $0-0$ \\
\hline
\end{tabular}

\section{Bloco III}

Tabela 12 - De a cordo com sua opinião qual ma téria deveria tra tar deste assunto:

\begin{tabular}{|c|c|c|}
\hline & $\begin{array}{l}5 \times 110 \\
N^{\prime \prime}-\%\end{array}$ & $\begin{array}{l}6 \pi+110 \\
N^{2}-4 \%\end{array}$ \\
\hline a) Psicologia & $36-80$ & $2-5$ \\
\hline b) Patologia & $0-0$ & $1 \%-42,5$ \\
\hline c) Disciplinas clinicas & $3-7$ & $8-20$ \\
\hline d) I'ropedêutica médica & $6-1.3$ & $1.3-32,5$ \\
\hline
\end{tabular}

Tabela 13 - Você acredita que durante o restante do curso o tema será abordado:

\begin{tabular}{|c|c|}
\hline & $\begin{array}{l}3^{\prime \prime} \text { तno } \\
N^{\prime \prime \prime}-\%\end{array}$ \\
\hline a) Acho que sim e considcro muito importante & $29-6 \times 4$ \\
\hline b) Acho que sim e năo considero importante & $1-2$ \\
\hline c) Acho que nao. mas considero muito importante & $13-29$ \\
\hline d) Acho que não e considtero pouco importante? & $2-5$ \\
\hline
\end{tabular}


Tabela 14 - O curso de Medicina ofereceu-lhe meios de lidar com a morte:

\begin{tabular}{|c|c|c|c|}
\hline & $\begin{array}{l}6 \pi n o \\
N-\%\end{array}$ & $\begin{array}{c}\text { Resicientes } \\
N^{\prime \prime}-\% /\end{array}$ & $\begin{array}{l}\text { Professores } \\
N^{\prime \prime}-\%\end{array}$ \\
\hline a) Otereceu todos os meios & $2-5$ & $1-12,5$ & $1-4$ \\
\hline b) Ofereceu o necessário & $5-12,5$ & $5-62,5$ & $5-21$ \\
\hline c) Ofereceu um pouco, mas não o necessário & $21-52,5$ & $0-0$ & $7-29$ \\
\hline d) Não ofereceu nada & $12-30$ & $0-0$ & $11-46$ \\
\hline
\end{tabular}

Tabela 15 - Em sua opiniāo, os livros e as revistas:

\begin{tabular}{lc}
\hline & $\frac{\text { Professores }}{N^{0}-\%}$ \\
\hline a) Disculem ahertamente o tema & $1-4$ \\
b) Discutem o necessário & $0-0$ \\
c) Discutem muito pouco & $17-71$ \\
d) Não discutem nada & $6-25$ \\
\hline
\end{tabular}

Tabela 16 - Você, como médico iniciante:

\begin{tabular}{|c|c|}
\hline " & $\begin{array}{l}3 \text { Ano } \\
N^{\prime \prime}-8\end{array}$ \\
\hline a) Tia aria naluralmente com a morte & $2-4$ \\
\hline b) Teria um pouco de dificuldade para lidar & $28-62$ \\
\hline c) Teria muila dificuldade para lidar & $15-.34$ \\
\hline d) Não saberia o que iazer & $0-0$ \\
\hline
\end{tabular}

Tabela 17 - Quando um paciente morre em suas mãos, você:

\begin{tabular}{|c|c|c|c|}
\hline & $\begin{array}{l}6 " \text { Ano } \\
N^{\prime \prime}-\%\end{array}$ & $\begin{array}{l}\text { Residentes } \\
N^{\prime \prime}-\%\end{array}$ & $\begin{array}{c}\text { Professores } \\
N^{\prime \prime}-\%\end{array}$ \\
\hline a) Sente-se muito mal e não conversa sobre o assunto & $5-12,5$ & $1-16,5$ & $1-4$ \\
\hline b) Sente-se muito mal e procura conversar sobre o assunto & $20-50,5$ & $4-66,5$ & $15-63$ \\
\hline c) Sente-se mal e procurar esquecer rapidamente & $11-27,5$ & $1-16,5$ & $3-13$ \\
\hline d) Nảo sente nada & $3-7,5$ & $0-0$ & $2-s$ \\
\hline
\end{tabular}

Tabela 18 - Que sensação você experimenta ao perder um paciente:

\begin{tabular}{lcc}
\hline & $\begin{array}{c}\text { Residentes } \\
N^{\prime \prime}-\%\end{array}$ & $\begin{array}{c}\text { Professores } \\
\mathrm{N}^{\prime \prime}-\%\end{array}$ \\
\hline a) Sensação de impotência e acha que poderia fazer mais & $1-16,5$ & $9-37$ \\
b) Sensação de impotencia, mas accita a limitação & $5-83$ & $13-54$ \\
c) Sensação de raiva por não poder tazer mais & $0-0$ & $0-0$ \\
d) Sensação de raiva, mas aceita a limitação & $0-0$ & $1-4$ \\
\hline
\end{tabular}

Tabela 19 - Por causa da morte, você já pensou em abandonar a Medicina:

\begin{tabular}{lcc}
\hline & Residentes & Professores \\
$N^{\prime \prime}-\%$ & $-\%$ \\
\hline a) Muitas vezes & $0-0$ & $1-4$ \\
b) Algumas vezes & $0-0$ & $2-8$ \\
c) Poucas vezes & $3-50$ & $3-1.3$ \\
d) Nunca & $3-50$ & $18-75$ \\
\hline
\end{tabular}

Tabela 20 - Os colegas e professores conversam:

\begin{tabular}{lc}
\hline a) Conversam muito sobre o assunto & Residentes \\
b) Conversam, mas näo o suticiente & $\%$ \\
c) Conversam raramente & $1-16,5$ \\
d) Nunca conversam sotree o assunto & $4-66,5$ \\
\hline
\end{tabular}


Tabela 21 - Você procura conversar com os alunos:

\begin{tabular}{|c|c|}
\hline & $\begin{array}{c}\text { Prolessores } \\
N^{\prime \prime}-\%\end{array}$ \\
\hline a) Conversa muito sobre o assunto & $3-13$ \\
\hline b) Conversa, mas nāo o suficiente & $12-50$ \\
\hline c) Conversa raramente & $7-29$ \\
\hline d) Nunca conversa sobre o assunto & $2-8$ \\
\hline \multicolumn{2}{|c|}{ Tabela 22 - Você a cha que os colegas: } \\
\hline & $\begin{array}{c}\text { Prolessores } \\
N^{\prime \prime \prime}-\%\end{array}$ \\
\hline a) Conversam muto sobre o assunto & $0-0$ \\
\hline b) Conversam, mas nå o suficiente & $5-21$ \\
\hline c) Conversam raramente & $18-75$ \\
\hline d) Nunica conversam sobre 0 assunto & $1-4$ \\
\hline
\end{tabular}

Tabela 23 - Na família, em caso de perda de parente próximo, você:

\begin{tabular}{lc} 
& $\frac{\text { Prolessores }}{N^{\prime \prime}-\%}$ \\
\hline a) Conversa muito & $6-2.5$ \\
b) Conversa, mas não o suficiente & $11-46$ \\
c) Conversa raramente & $5-21$ \\
d) Nunca conversa sobre. o assunto & $1-4$ \\
\hline
\end{tabular}

Tabela 24 - Você acha que a profissão fez com que melhorasse sua relação com a morte:

\begin{tabular}{lc} 
& Protessores \\
& $N^{0}-\%$ \\
\hline a) Sim & $17-70$ \\
b) Não & $6-25$ \\
\hline
\end{tabular}

Tabela 25 - Como você vê Deus diante da morte?

\begin{tabular}{lc}
\hline a) : Nacha lem a ver & $\begin{array}{c}\text { Professores } \\
N "-~ " 3 \%\end{array}$ \\
b) Revolto me contra Deus & $4-17$ \\
c) Aceito como um desígnio de Deus & $1-4$ \\
d) Nāo misturo minha fé com meu trabalho & $9-37$ \\
\hline
\end{tabular}

Tabela 1B - Diz Royo: "Para mim, que sou um otimista, a vida, por pior que seja, é sempre a vida; prefiro viver tarado com todos os estigmas, saturado de mil enfermidades, coberto de todos os opróbrios... a não viver".

Se Royo fosse seu paciente e estivesse em fase final de carcinomatose, você:

\begin{tabular}{|c|c|c|}
\hline & $\frac{\text { Residenles }}{N^{\prime \prime}-\%}$ & $\begin{array}{c}\text { Protessores } \\
N^{\prime \prime}-\%\end{array}$ \\
\hline a) Respeitaria o direito de e e taria ludo para manté-To vivo & $3-50$ & $16-67$ \\
\hline b) Respeitaria o direito em termos, nada faria para prolongar a vida ${ }^{-}$ & $3-50$ & $7-29$ \\
\hline c) Não respcitaria o direito e aceleraria a morte & $0-0$ & $0-0$ \\
\hline
\end{tabular}

Tabela 2B - Diz Ariosto: "A última vitória da Medicina - frente à sua impotência científica -, quando é impossível triunfar sobre o mal incurá vel, será adormecer o agonizante na tranqüila sonolência medicamentosa que leva ao letargo e à morte total, sua vemente".

Se Ariosto fosse seu paciente e estivesse em fase final de carcinoma tose, você:

\begin{tabular}{|c|c|c|}
\hline & $\begin{array}{c}\text { Residentes } \\
N^{* \prime}-\%\end{array}$ & $\begin{array}{c}\text { Professores } \\
N^{\prime \prime}-\%\end{array}$ \\
\hline a) Kespeilaria o direito dele e laria ludo para manté-To vivo & $1-16,5$ & $9-38$ \\
\hline b) Respeitaria o direito em termo:s, nada faria para prolongar a vida & $4-66,5$ & $12-50$ \\
\hline c) Năo respeitaria o direito e aceleraria a morte & $1-16,5$ & $2-8$ \\
\hline
\end{tabular}


Tabela 3B - Você doou seus órgãos:

\begin{tabular}{lc} 
& Erofessorcs \\
\hline a) Simu & $N^{\prime \prime}-\%$ \\
b) Nāo & $10-42$ \\
c) Nāo responderam & $11-45$ \\
\hline
\end{tabular}

Tabela 4B - Não doou por:

\begin{tabular}{lc}
\hline & Professores \\
& $N^{\prime \prime}-\%$ \\
\hline a) Nảo ter pensado na morte & $8-3.3,3$ \\
b) Não estar preparado para isso & $8-3.3,3$ \\
c) Não responderam & $8-3.3,3$ \\
\hline
\end{tabular}

\section{Bloco III}

Tabela 1A - "Mas agora não sinto falta \(É sempre assim quando o a usente \Partiu sem se despedir:\Você não se despediu.)\Você não morreu: ausentou-se..." Manuel Bandeira Você tem essa sensação de ausência ante a morte:

\begin{tabular}{|c|c|c|c|c|c|}
\hline & $\begin{array}{l}\text { 1"Nono } \\
\text { N"- } \%\end{array}$ & $\begin{array}{l}3 \text { Ano } \\
N^{\prime \prime}-\%\end{array}$ & $\begin{array}{l}6^{n} \text { Ano } \\
\text { N - } \%\end{array}$ & $\begin{array}{c}\text { Residentes } \\
N^{\prime \prime}-\%\end{array}$ & $\begin{array}{c}\text { Prolessores } \\
N^{\prime \prime}-\%\end{array}$ \\
\hline a) Sempre & $19-28$ & $11-24$ & $12-30$ & $3-50$ & $3-1.3$ \\
\hline b) A maioria das vezes & $36-53$ & $18-40$ & $12-30$ & $2-33$ & $10-41$ \\
\hline c) Poucas vezes & $10-15$ & $1.3-29$ & $8-20$ & $0-0$ & $7-29$ \\
\hline d) Nunca & $3-4$ & $3-7$ & $5-12,5$ & $0-0$ & $4-17$ \\
\hline
\end{tabular}

Tabela 2A - Você considera essa sensação de ausência ante a morte:

\begin{tabular}{|c|c|c|c|c|c|}
\hline & $\begin{array}{l}\text { T"Ano }^{\prime \prime} \text { A } \\
N^{\prime \prime \prime}-\%\end{array}$ & $\begin{array}{l}3 \text { Ano } \\
N^{*}-(\%)\end{array}$ & $\begin{array}{l}6 \text { Ano } \\
N^{\prime \prime}-\%\end{array}$ & $\begin{array}{c}\text { Residentes } \\
N^{\prime \prime}-6 / 6\end{array}$ & $\begin{array}{l}\text { Professores } \\
N^{\prime \prime}-(1 / 1)\end{array}$ \\
\hline a) Crma forma satisłatória de reaçāo & $49-72$ & $28-612$ & $22-.55$ & $5-83$ & $15-62$ \\
\hline b) Um modo freqüente e anormal de reaçāo & $9-1.3$ & $5-11$ & $5-12,5$ & $8-20$ & $5-12,5$ \\
\hline d) Um modo freqüente e inadequado de reagir & $7-11$ & $11-24$ & $8-20$ & $0-0$ & $4-17$ \\
\hline d) L'm modo infreqüente e inadequado de reagir & $3-4$ & $1-2$ & $5-12,5$ & $0-0$ & $1-4$ \\
\hline
\end{tabular}

Tabela 3A - Você acha que o médico:

\begin{tabular}{|c|c|c|c|c|c|}
\hline & $\begin{array}{l}T: A: O \\
N=-\%\end{array}$ & $\begin{array}{l}3^{\circ} \pi{ }^{\circ} \\
N^{\prime \prime}-\%\end{array}$ & $\begin{array}{l}6^{\prime \prime} A 10 \\
N^{\prime \prime}-Y_{6}^{\prime}\end{array}$ & $\begin{array}{c}\text { Residentes } \\
N^{\prime \prime}-\%\end{array}$ & $\begin{array}{c}\text { Prolessores } \\
\mathrm{N}^{\mathrm{in}}-\%\end{array}$ \\
\hline a) Aprende a conviver com a morte & $44-65$ & $29-64$ & $29-72,5$ & $3-50$ & $16-66$ \\
\hline b) Nega para conseguir conviver com ela & $3-4$ & $10-22$ & $4-10$ & $2-33$ & $3-1.3$ \\
\hline c) Sai da faculdade em condiçōes de lidar & $6-9$ & $2-4,5$ & $1-2,5$ & $0-0$ & $1-4$ \\
\hline d) Nunca aprende a conviver com a morte & $15-22$ & $3-6,5$ & $6-15$ & $0-0$ & $4-17$ \\
\hline
\end{tabular}

Tabela 4A - A necessidade de acreditar na imortalidade:

\begin{tabular}{|c|c|c|c|c|c|}
\hline & $\begin{array}{l}1^{\prime \prime} \text { Ano } \\
N^{\prime \prime \prime}-\%\end{array}$ & $\begin{array}{l}3 \text { Ano } \\
\mathrm{N}^{\prime \prime}-\%\end{array}$ & $\begin{array}{l}\sigma^{\prime \prime}-\sqrt{n 10} \\
N^{\prime \prime}-\%\end{array}$ & $\begin{array}{l}\text { Residentes } \\
N^{\prime \prime}-\%\end{array}$ & $\begin{array}{c}\text { Professores } \\
N^{(1)}-\%\end{array}$ \\
\hline a) Emuito lreqüente entre os homens & $32-47$ & $19-42$ & $18-4.5$ & $1-16,5$ & $8-33$ \\
\hline b) É freqüente entre os homens & $29-4.3$ & $22-49$ & $16-40$ & $3-50$ & $13-54$ \\
\hline c) $\dot{E}$ pouco freqüente entre os homens & $7-10$ & $4-9$ & $5-12,5$ & $1-16,5$ & $3-13$ \\
\hline d) Nunciaocone entre os homens & $0-0$ & $0-0$ & $1-2,5$ & $0-0$ & $0-0$ \\
\hline
\end{tabular}

Tabela 5A-Quanto à necessidade de os médicos adquirirem formas de se relacionar com a perda:

\begin{tabular}{|c|c|c|c|c|c|}
\hline & $\begin{array}{l}I^{0} \text { Ano } \\
\left.N^{\prime \prime \prime}-\%\right)\end{array}$ & $\begin{array}{l}3 \text { Ano } \\
N^{*}-\%\end{array}$ & $\begin{array}{l}6 \text { Ano } \\
N^{4}-\%\end{array}$ & $\begin{array}{c}\text { Residentes } \\
N^{\prime \prime}-\%\end{array}$ & $\begin{array}{c}\text { Professores } \\
N^{\prime \prime}-\%\end{array}$ \\
\hline a) Enecessario para atuarem & $62-91$ & $45-100$ & $35-87.5$ & $5-83$ & $2.3-96$ \\
\hline b) É desnecessário para aluarem & $0-0$ & $0-0$ & $1-2,5$ & $0-0$ & $0-0$ \\
\hline c) Os despreparados que procurem outra profissâo & $5-7$ & $0-0$ & $0-0$ & $0-0$ & $0-0$ \\
\hline d) O médico deve se preocupar com a vida & $1-2$ & $0-0$ & $4-10$ & $0-0$ & $0-0$ \\
\hline
\end{tabular}


Tabela 6A-Para você, a frequiência de suicídios entre os médicos com a sensação de impotência:

\begin{tabular}{|c|c|c|c|c|c|}
\hline & $\begin{array}{l}T^{A} \text { Ano } \\
N-1 / 1 / 2\end{array}$ & $\begin{array}{l}3 \times \text { no } \\
N^{n}-\%\end{array}$ & $\begin{array}{l}6 \text { Ano } \\
N^{\prime \prime}-w_{d}\end{array}$ & $\begin{array}{c}\text { Residentes } \\
N^{\prime \prime}-M^{\prime \prime}\end{array}$ & $\begin{array}{l}\text { Professores } \\
N^{\circ}-w_{1}^{\circ}\end{array}$ \\
\hline a) Tem tudo a ver com ch & $9-1.3$ & $5-11$ & $2-5$ & $0-0$ & $1-4$ \\
\hline b) Tem muito a ver com ela & $40-54$ & $29-64$ & $17-42,5$ & $2-.33$ & $5-21$ \\
\hline c) Tem pouco a ver com ela & $17-25$ & $7-16$ & $2-3.3$ & $3-50$ & $7-29$ \\
\hline d) Nāo tem a ver com ela & $2-3$ & $4-9$ & $5-21$ & $0-0$ & $11-46$ \\
\hline
\end{tabular}

\section{Bloco IV (Questões abertas)}

Tabela 1C - Escreva duas palavras que sintonizem sua visão da morte:

\begin{tabular}{|c|c|c|c|c|c|}
\hline & $\begin{array}{l}\mathrm{T}^{\prime} \text { Ano } \\
\mathrm{N}^{\prime}-\%\end{array}$ & $\begin{array}{l}3 \text { Ano } \\
N^{\prime \prime}-\%\end{array}$ & $\begin{array}{l}6 \text { Ano } \\
N^{\prime}-\%\end{array}$ & $\begin{array}{c}\text { Residentes } \\
N^{\prime \prime}-(\%)\end{array}$ & $\begin{array}{c}\text { Proressores } \\
N^{\prime \prime}-(x)\end{array}$ \\
\hline $\begin{array}{l}\text { Grupo T Tmudança, renovaçāo, liberdade, início e } \\
\text { descanso) }\end{array}$ & $31-2.3$ & $12-15$ & $8-11$ & $5-42$ & $4-9$ \\
\hline $\begin{array}{l}\text { Grupo Il (passagem, saudade, ausência, inevitável, } \\
\text { solidão e mistério) }\end{array}$ & $46-35$ & $.3 .3-4.3$ & $19-28$ & $3-25$ & $29-66$ \\
\hline Grupo III (tristeza, fim, perda, medo e sofrimento) & $55-42$ & $.32-42$ & $42-61$ & $4-3.3$ & $11-25$ \\
\hline Tolal de respostas & 1.32 & 77 & 69 & 12 & $4 \cdot 4$ \\
\hline
\end{tabular}

Tabela 2C - Escreva três palavras que expressem um conceito sobre o significado de vida:

\begin{tabular}{|c|c|c|c|c|c|}
\hline & $\begin{array}{l}1^{\prime \prime} \text { Ano } \\
N^{\prime \prime}-(\%)\end{array}$ & $\begin{array}{l}3 \text { Ano } \\
N^{\prime \prime}-w^{\prime \prime}\end{array}$ & $\begin{array}{l}6^{\prime \prime} \text { Ano } \\
N^{\prime \prime}-\%\end{array}$ & $\begin{array}{l}\text { Residentes } \\
\text { N"- } \%\end{array}$ & $\begin{array}{l}\text { Professores } \\
\qquad N^{\prime \prime}-(y)\end{array}$ \\
\hline $\begin{array}{l}\text { Grupo Thalegria, amor, saude, aprendizado, } \\
\text { felicidade, trabalho e esperancia) }\end{array}$ & $96-56$ & $90-67$ & $77-77$ & $10-55,5$ & $40-68$ \\
\hline $\begin{array}{l}\text { Cirupo II (familia, sentimento, solidaricdade e } \\
\text { relacionamento) }\end{array}$ & $52-.31$ & $20-15$ & $15-15$ & $3-16,5$ & $15-25$ \\
\hline Cirtupo III (dificuldade e sofrimento) & $22-13$ & $25-18$ & $8-8$ & $5-28$ & $4-7$ \\
\hline Total de respostas & 170 & 1.35 & 100 & 18 & 59 \\
\hline
\end{tabular}

Tabela 3C - Escreva três palavras sobre os sentimentos que você experimentou ao responder o questioná rio:

\begin{tabular}{|c|c|c|c|c|c|}
\hline & $\begin{array}{l}1^{1} \mathrm{AnO} \\
\mathrm{N}\end{array}$ & $\begin{array}{l}3 \times n o \\
N^{n}-\%\end{array}$ & $\begin{array}{l}\text { G"Ano }^{\prime \prime} \\
N^{0}-Q, y,\end{array}$ & $\frac{\text { Eesidentes }}{N^{\prime \prime}-\%}$ & $\begin{array}{l}\text { Professores } \\
N^{*}-\%\end{array}$ \\
\hline $\begin{array}{l}\text { Grupo Thellexão, interesse, curiosidade, saucie, } \\
\text { aprendizado, felicidade, trabalho e esperança) }\end{array}$ & (19) -45 & $40-4.3$ & $28-.30$ & $6-3.3$ & $23-36$ \\
\hline $\begin{array}{l}\text { Grupo II (sinceridade, normalidade, realidade e } \\
\text { dúvida) }\end{array}$ & $56-.37$ & $28-.30$ & $23-24$ & $2-11$ & $2.3-.36$ \\
\hline Crupo III (angústia, bisteza e medo) & $27-18$ & $24-27$ & $43-46$ & $10-55$ & $17-27$ \\
\hline Total de respostas & 152 & 92 & 94 & 18 & 6.3 \\
\hline
\end{tabular}

Tabela $4 \mathrm{C}$-Cite duas disciplinas de $1^{\circ}$ e $2^{\circ}$ anos que deveriam privilegiar a morte como tema:

\begin{tabular}{|c|c|c|c|c|}
\hline & 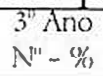 & $\begin{array}{l}6^{\prime \prime} \text { Ano } \\
N^{\prime \prime}-" \text { '紧 }\end{array}$ & $\begin{array}{c}\text { Residentes } \\
N^{\prime \prime}-\%\end{array}$ & $\begin{array}{c}\text { Professores } \\
N^{\prime \prime \prime}-1 / 1 /\end{array}$ \\
\hline Psicologia e alins & $38-49$ & $2 \cdot 4-.36$ & $6-36$ & $6-17$ \\
\hline Saúde c Contexto & $28-36$ & $1-1,5$ & $0-0$ & $2-5,5$ \\
\hline Estudo do Homem Contemporâneo & $6-8$ & $2-1,5$ & $2-1.5$ & $1-2.5$ \\
\hline Anatomia e Patologia & $3-4$ & $6-1$ & $0-0$ & $2-5,5$ \\
\hline Medicina Legal & $0-0$ & $10-15$ & $3-15$ & $8-2.3$ \\
\hline Clínicas & $0-0$ & $13-21$ & $0-0$ & $6-17$ \\
\hline Semiologia & $2-3$ & $3-4,5$ & $0-0$ & $2-5.5$ \\
\hline Outras & $0-0$ & $8-12$ & $1-1$ & $8-2.3$ \\
\hline
\end{tabular}


Tabela 5C - Cite duas palavras relacionadas com a morte:

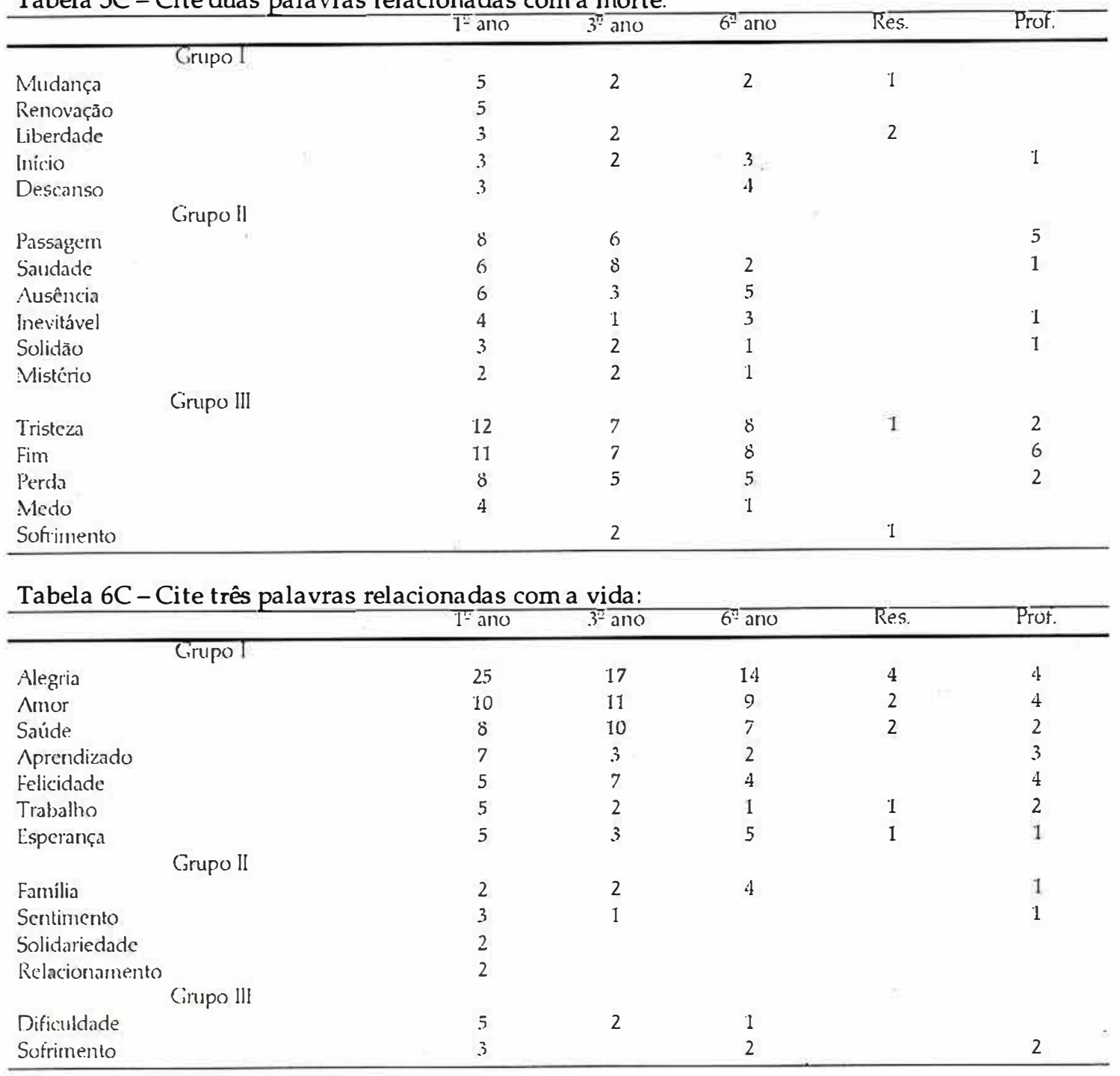

Tabela 7C - Cite três palavras relacionadas com o questionário:

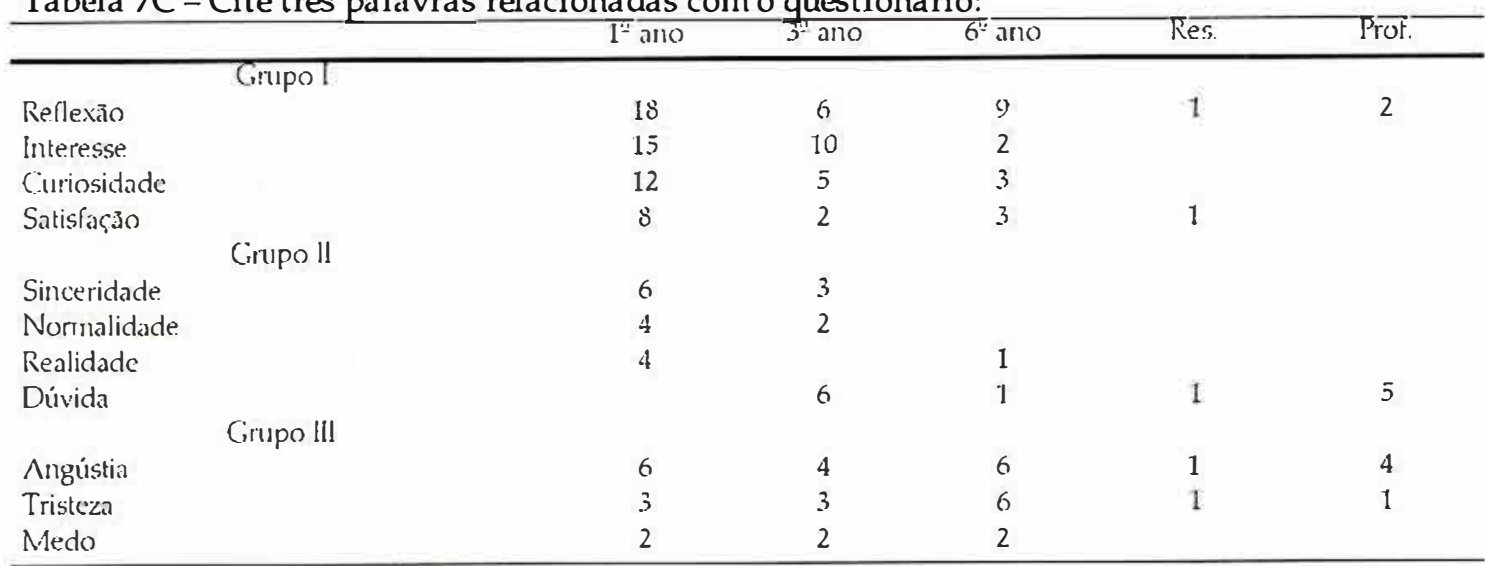

